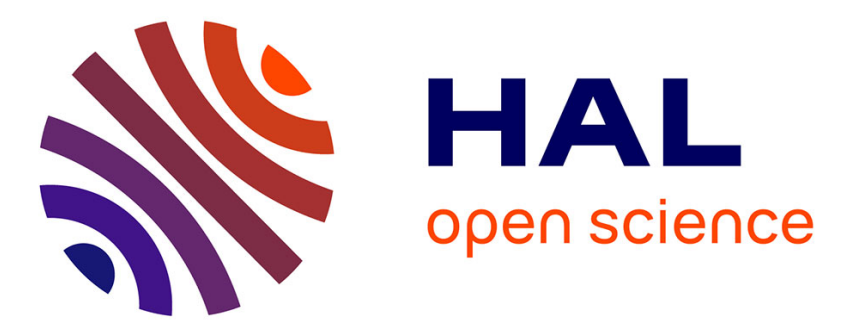

\title{
Ironless and leakage free voice-coil motor made of bonded magnets
}

\author{
Mathias Remy, Guy Lemarquand, Bernard Castagnede, Gaël Guyader
}

\section{To cite this version:}

Mathias Remy, Guy Lemarquand, Bernard Castagnede, Gaël Guyader. Ironless and leakage free voice-coil motor made of bonded magnets. IEEE Transactions on Magnetics, 2008, 44 (11), pp.4289. 10.1109/TMAG.2008.2003401 . hal-00413628

\section{HAL Id: hal-00413628 \\ https://hal.science/hal-00413628}

Submitted on 4 Sep 2009

HAL is a multi-disciplinary open access archive for the deposit and dissemination of scientific research documents, whether they are published or not. The documents may come from teaching and research institutions in France or abroad, or from public or private research centers.
L'archive ouverte pluridisciplinaire HAL, est destinée au dépôt et à la diffusion de documents scientifiques de niveau recherche, publiés ou non, émanant des établissements d'enseignement et de recherche français ou étrangers, des laboratoires publics ou privés. 


\title{
Ironless and leakage free voice-coil motor made of bonded magnets
}

\author{
M. Remy ${ }^{1,2}$, G. Lemarquand ${ }^{1}$, B. Castagnede ${ }^{1}$, G. Guyader $^{2}$ \\ ${ }^{1}$ Laboratoire d'Acoustique de l'Universite du Maine UMR CNRS 6613, 72085 Le Mans Cedex 9, France \\ ${ }^{2}$ Technocentre Renault, 78288 GUYANCOURT, France
}

\begin{abstract}
This paper reminds the drawbacks of classical voicecoil motors and presents a way to improve them. Two ironless and leakage free structures are presented, one using traditional sintered magnets and the other one using bonded magnets, giving the pros and cons of each solution. A $2 \mathrm{D}$ analytical model using the Coulombian approach is used to calculate and compare the performances of both structures. Then, in order to evaluate the relevance of the $2 \mathrm{D}$ model for magnet rings, a comparison is done with a 3D analytical model for several radii of rings.
\end{abstract}

Index Terms-Bonded magnets, loudspeakers, magnetic field analytical calculations, permanent magnet rings

\section{INTRODUCTION}

V OICE-COIL MOTORS, such as those used in traditional electrodynamic loudspeakers, present a number of wellknown drawbacks [1], [2].

First, the presence of iron in such motors leads to several kinds of nonlinearities. These include Eddy currents, the magnetic saturation of the iron and the variation of the coil inductance with its position causing a reluctant effect. However, it is desirable for the force applied on the moving part to be an image of the driving current. The driving forces applied on the moving part of the loudspeaker can be written as

$$
F_{d r i v}=F_{L}+F_{r}=B l i+\frac{1}{2} \frac{d L}{d x} i^{2}
$$

where $F_{L}$ is the Laplace force, $F_{r}$ the reluctant force, $B$ the induction seen by the voice-coil, $l$ the length of the coil, $i$ the driving current flowing through the coil, $L$ the inductance of the coil and $x$ the displacement of the coil. Thus, (1) shows that if the inductance of the coil varies, a reluctant force, proportional to $i^{2}$, occurs and interferes with the Laplace force. This reluctant force creates a force distortion resulting directly in an audible acoustical distortion. It can be compared to the cogging torque in brushless motors, arising from a reluctant effect, which prevents a smooth rotation of the motor and results in undesirable vibration and noise [3], [4]. In order to solve these problems, several structures of ironless voicecoil motors have already been proposed [5], [6], [7], [8]. With such structures, the inductance of the coil no longer depends on its position, resulting in the vanishing of the reluctant force and the other nonlinearities due to iron listed previously. In addition, the inductance is diminished and consequently, so is the electrical impedance, especially at high frequencies.

Second, a significant part of the magnetic field created by most loudspeaker motors does not contribute towards making

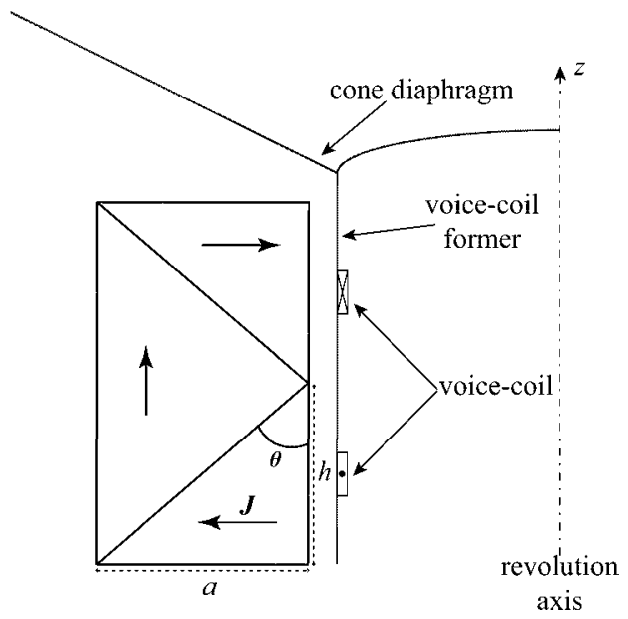

Fig. 1. Cross section of the three sintered magnets structure.

the membrane move. In addition to a simple loss of magnetic field, this leakage flux can be attracted by any ferromagnetic object placed nearby, leading to a decrease of the device efficiency. Reciprocally, this leakage magnetic field can prevent some devices placed nearby from working properly. Therefore, another intended specification of the motor is to have a minimized magnetic field leakage.

This paper compares the efficiency of two ironless and leakage free motor structures. The first one is made of traditional sintered magnets whereas the second one is made of bonded magnets. The first part of this paper describes in details the two structures and the analytical model used to calculate their created magnetic field. In the second part, their performances are calculated and compared for a particular example. Finally, a comparison between $2 \mathrm{D}$ and $3 \mathrm{D}$ analytical modeling is presented.

\section{Theoretical Model}

\section{A. Description of the Structures}

An example of ironless and leakage free motor structure made totally of sintered permanent magnets is shown in Fig. 1. It is composed of three prismatic magnet rings arranged in such a way that the magnetization is always parallel to the outer edge. Thus, the whole magnetic field created by the motor is focused on the voice-coil path. However, one problem with the structures made of sintered magnets is that it can be 


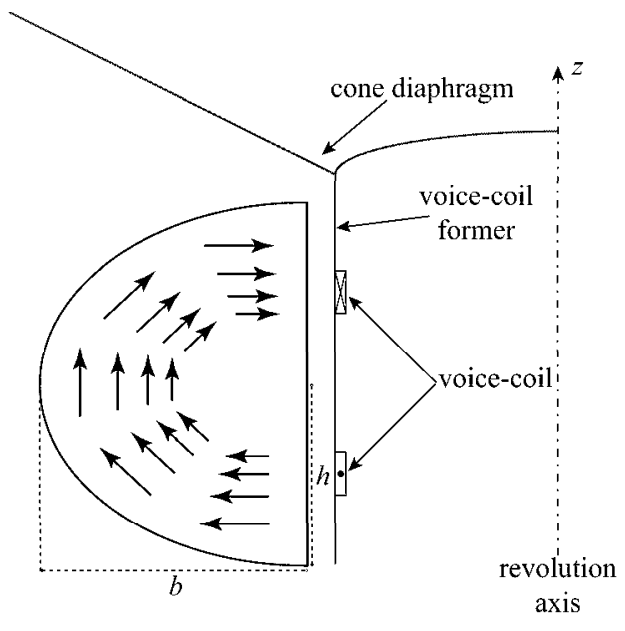

Fig. 2. Cross section of the bonded magnets structure.

difficult to assemble. The structure shown in Fig. 1 requires the fabrication of three magnet rings, two of them being radially magnetized which is not easy to achieve.

By using bonded magnets, this problem can be solved and furthermore, better cross section shapes and optimized magnetization of the structure can be realized. The whole structure is directly injected in a mold and no assembly is needed. One possible leakage free structure made of bonded magnets is presented in Fig. 2. The structure that we propose has an ellipsoidal cross section. The magnetization is realized when the material is still liquid so that the magnetic particles follow the magnetic field lines created by the magnetizer. Once again, the magnetization of the structure is done so that it is always tangent to the outer edge except on the side facing the voice-coil, where it is perpendicular to the edge. The magnetic field created by the motor is then concentrated on the voicecoil path in order to increase the efficiency of the loudspeaker.

Another advantage of these structures is that a double coil winding can be used to improve the efficiency. Furthermore, the magnetic field created by these structures presents a high gradient around the semi-height of their inner face. This high magnetic field gradient permits the use of ferrofluid seals to guide the moving part [9]. Ferrofluid seals have also a role of thermal bridge, allowing the heat created by the voice-coil to flow through and be dissipated in the motor.

\section{B. Analytical Model}

The 2D Coulombian approach is used to calculate analytically the magnetic field created by the structures illustrated in Fig. 1 and 2 [10], [11]. The ellipsoidal motor (Fig. 2) is discretized in order to enable analytical calculations of the magnetic field to be performed. This discretization, using seven magnets of equal angular section, is shown in Fig. 3.

A magnetic charges model is used to describe the magnets. The surface charge density $\sigma^{*}$ of each triangular magnet is defined with the magnetization $\vec{J}$ and then calculated such as

$$
\sigma^{*}=\vec{J} \cdot \vec{n}
$$

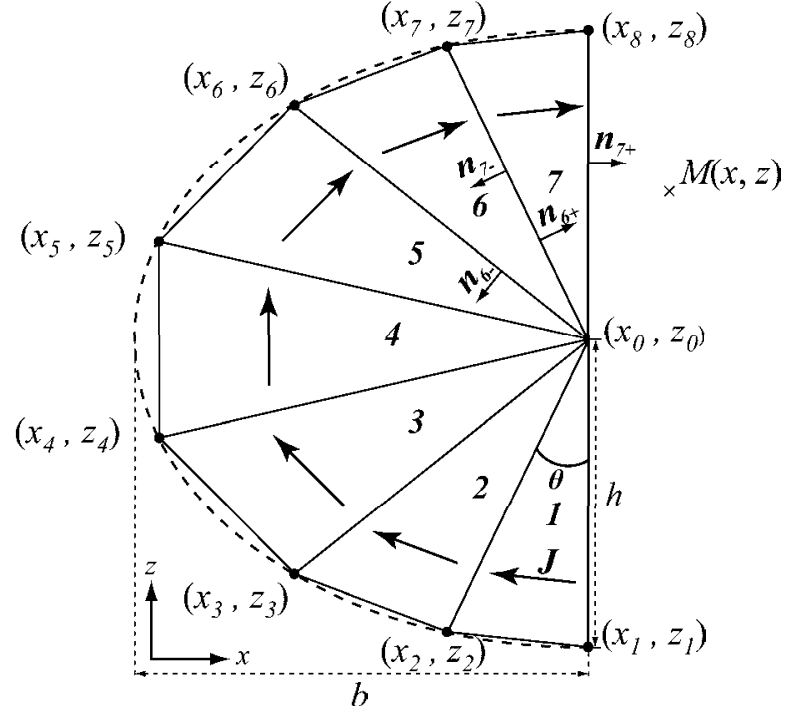

Fig. 3. Cross section of the discretized bonded magnets structure used for analytical calculations.

where $\vec{n}$ is the outwards surface normal vector. The magnetization is considered to be always parallel to the outer edge of the ellipsoid in order to avoid magnetic flux leakages. As a result, the magnetization is uniform for each magnet, which gives

$$
\operatorname{div} \vec{J}=\rho^{*}=0
$$

where $\rho^{*}$ represents the volume charge density. Nevertheless, for the real structure, volume charges should be taken into account, as in [12].

The magnetic field, $\vec{B}$, created by each magnet surface at any point $M(x, z)$ is given in $2 \mathrm{D}$ by

$$
\vec{B}=\frac{\sigma^{*}}{4 \pi} \int_{y_{i}=-\infty}^{y_{i}=+\infty} \int_{z_{i}} \frac{\overrightarrow{P M}}{|\overrightarrow{P M}|^{3}} d y_{i} d z_{i}
$$

where $P\left(x_{i}, z_{i}\right)$ is a point on the considered surface $i$. Thus, the magnetic field $\vec{B}$ can be expressed as

$\vec{B}=\frac{J}{4 \pi} \int_{y_{i}=-\infty}^{y_{i}=+\infty} \int_{z_{i}} \frac{\left(x-x_{i}, y-y_{i}, z-z_{i}\right)}{\left(\left(x-x_{i}\right)^{2}+\left(y-y_{i}\right)^{2}+\left(z-z_{i}\right)^{2}\right)^{\frac{3}{2}}} d y_{i} d z_{i}$

where $x_{i}$ is expressed as a function of $z_{i}$ in order to be able to integrate with a surface element $d y_{i} d z_{i}$.

Overall, the magnetic field created by the fourteen surfaces, two for each magnet, has to be calculated independently then summed to obtain the total magnetic field created by the ellipsoidal structure, since the superposition theorem applies. The same method is used to calculate the magnetic field created by the three magnets structure. It can be noted that for the rectangular structure, if $\theta$ equals $45^{\circ}$ (i.e. $a=h$ ), only the two surfaces facing the voice-coil have to be taken into account. This is due to the fact that the remaining surface charge density is equal to zero on the two other magnet interfaces. 


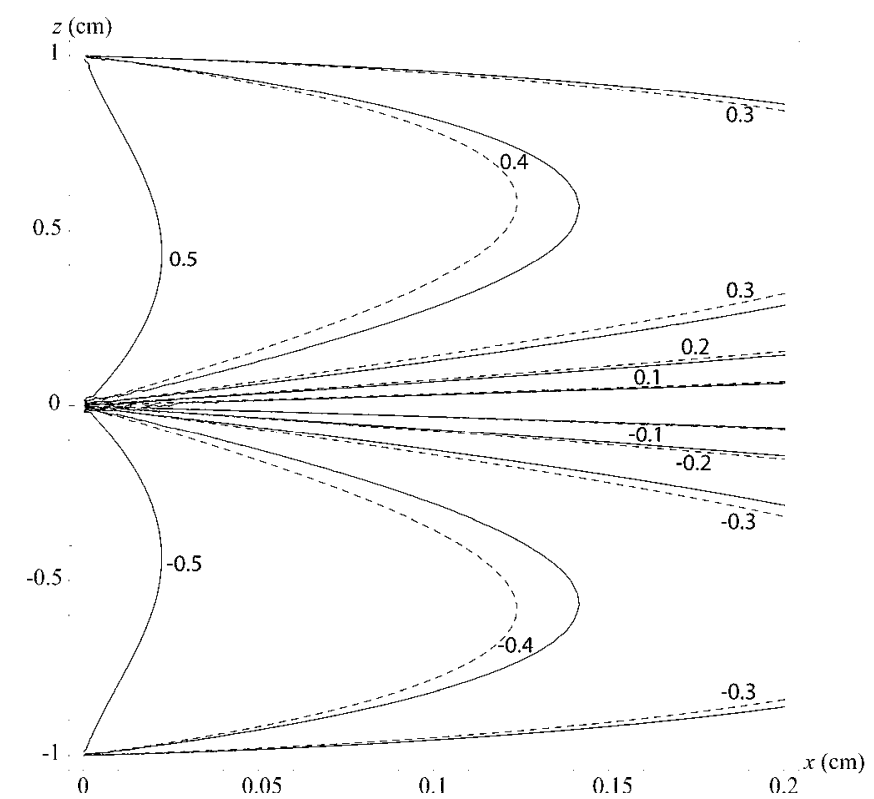

Fig. 4. Magnitude isolines of the $x$-component of the magnetic field created (in Tesla) by the rectangular section structure (dashed line) and the one created by the ellipsoidal section structure (solid line) of same volume.

\section{THEORETICAL RESULTS}

\section{A. Comparison of the Two Structures Performances}

In order to compare the performances of the two ironless structures presented in Fig. 1 and 2, numerical applications are done. The semi-height, $h$, equals $1 \mathrm{~cm}$ and the width, $a$, of the rectangular structure is taken equal to $h$. We decide to compare the magnetic fields created by two structures having the same cross section area. This condition leads to $b$ equals $1.27 \mathrm{~cm}$ for the ellipsoidal structure. For a general purpose, we consider that the magnetization of each magnet is equal to $1 \mathrm{~T}$. However, it is easy to recalculate for other values of $J$ since all the results are proportional to this former. Actually, with Neodymium-Iron-Boron (Nd-Fe-B) bonded magnets, it is difficult to obtain a magnetization bigger than 0.8 or $0.9 \mathrm{~T}$ whereas $\mathrm{Nd}-\mathrm{Fe}-\mathrm{B}$ sintered magnets can have a magnetization up to about $1.5 \mathrm{~T}$. Nevertheless, Nd-Fe-B sintered magnets are not commonly used in loudspeakers because of their price. Most of the loudspeakers still use hard ferrite magnets whose magnetization is around $0.4 \mathrm{~T}$.

Figure 4 presents the magnitude isolines of the $\mathrm{x}$-component of the magnetic field, $B_{x}$, created in front of the magnet for both structures. It is clear that the ellipsoidal structure gives better results than the rectangular one: the created magnetic field, $B_{x}$, is more intense and shows a better symmetry around the rest position of the voice-coil (i.e. $z$ equals 0.5 and -0.5 $\mathrm{cm})$.

Figure 5 compares the evolution of $B_{x}$ in front of the whole height of both magnet structures (i.e. $z$ equals $-1 \mathrm{~cm}$ to $z$ equals $1 \mathrm{~cm}$ ) at a distance $x$ from the magnet equal to $0.5 \mathrm{~mm}$ which is a typical distance for loudspeaker applications. Once again, it clearly shows that the ellipsoidal structure gives better results (i.e. intensity and symmetry around the rest position of the coil) than the rectangular one of equal magnet volume.

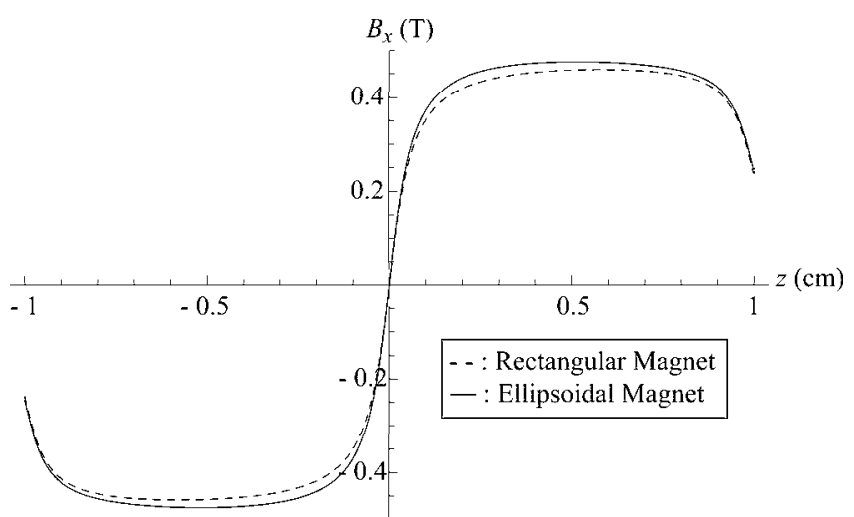

Fig. 5. x-component of the magnetic field created by the rectangular section structure (dashed line) and the onc created by the ellipsoidal scetion structure (solid line) of same volume along the height of both structures for $x=0.5 \mathrm{~mm}$.

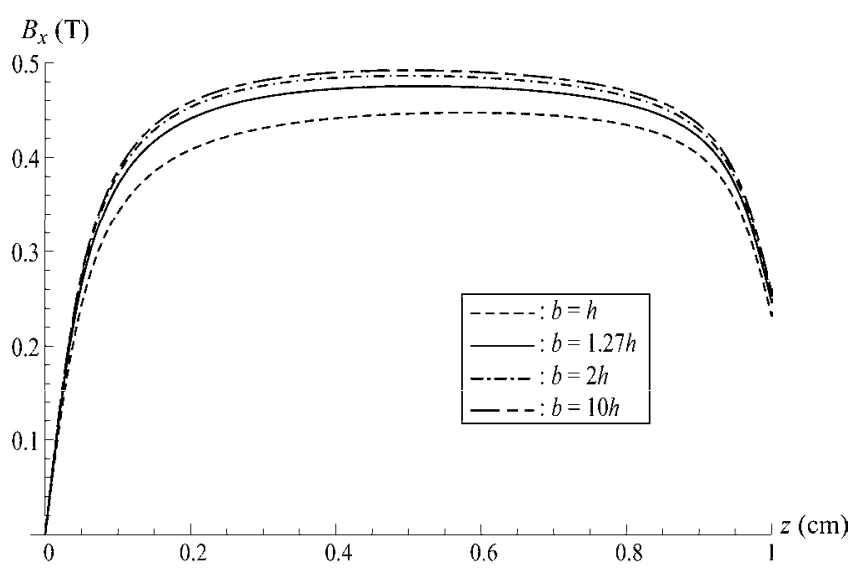

Fig. 6. Effect of the ratio between the lengths of the major axis $b$ and the minor axis $h$ of the ellipsoidal structure on the created magnetic field at $x=0.5 \mathrm{~mm}$

The symmetry around the rest position and the uniformity of the induction across the whole voice-coil trajectory is an important characteristic for an accurate loudspeaker motor. The length of this trajectory is determined by the intended acoustical pressure at low frequencies, giving the maximal needed acoustic flow, and thus, the maximal required excursion for a given radiating surface. For example, to obtain a sound pressure level of $95 \mathrm{~dB}$ SPL at $1 \mathrm{~m}$ on axis and at $100 \mathrm{~Hz}$ with a loudspeaker having a $5 \mathrm{~cm}$ radius membrane, the required excursion is $\pm 2 \mathrm{~mm}$. If we consider this oscillation range around the rest position, the difference of magnetic field intensity between the lowest and the highest position of the coil is $1 \%$ for the ellipsoidal structure and $3 \%$ for the rectangular one, which is significant for a loudspeaker. The uniformity of the magnetic field on the voice-coil path has a direct impact on the linearity of the transducer and thus, on its sound reproduction fidelity.

We now study the effect of the ratio between the lengths of the major axis $b$ and the minor axis $h$ of the ellipsoidal structure on the created magnetic field. Figure 6 shows that 


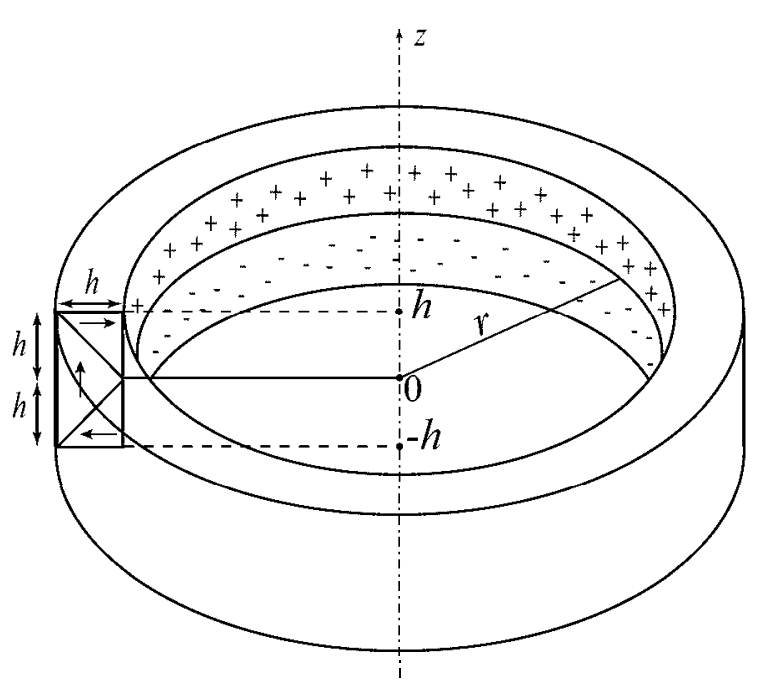

Fig. 7. 3D geometry used to estimate the validity of the $2 \mathrm{D}$ model.

when the ratio augments, the magnetic field intensity $B_{x}$ gets bigger and the symmetry around the rest position of the coil improves. However, over a certain value of this ratio, the increase in magnetic field intensity is negligible compared to the rise of volume. The ratio $b=2 h$ seems to be a good compromise between magnetic field intensity and magnet volume.

\section{B. Comparison with the $3 D$ Model}

All the results presented in the previous section were obtained with 2D analytical calculations. In order to evaluate the validity of the $2 \mathrm{D}$ model for magnet rings, we compare them to $3 \mathrm{D}$ analytical calculations for several inner radii of the ring. However, it would be really difficult to calculate analytically the ellipsoidal structure in 3D. A simplified structure, corresponding to the rectangular structure for $a=h$ (Fig. 7), is used to estimate the relevance of the $2 \mathrm{D}$ model. Figure 8 shows the magnetic field created by the structure from $z=-h$ to $z=h$ at a distance $x=0.5 \mathrm{~mm}$ calculated with the 2D model and with the 3D model for four different radii, using the 3D analytical formulas published recently by Ravaud et al. [13].

We notice that the 2D model gives a good approximation for big radii (e.g. $r>10 \mathrm{~cm}$ ) but becomes less accurate when the radius gets smaller than $5 \mathrm{~cm}$. For example, if $r=1 \mathrm{~cm}$, the difference between the 2D and the 3D calculations goes up to $40 \%$. However, 3D analytical calculations are really difficult to carry out, even for simple structures. So far, 2D calculations have been widely used, especially for the development of new structures, because of their practical use compared to finite element modeling. Nevertheless, it should be kept in mind that the accuracy of $2 \mathrm{D}$ results is not really good for radii of rings smaller than about $5 \mathrm{~cm}$ but still acceptable when looking at the magnetic field really close to the magnet.

\section{CONCLUSION}

This paper presents two leakage free structures of ironless motors, one made of traditional sintered magnets and the other

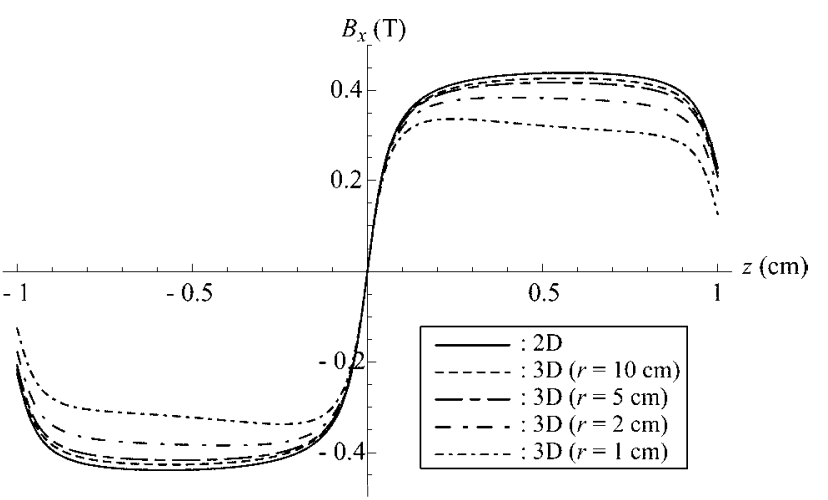

Fig. 8. Theoretical results of the magnetic field created by the structure shown in Fig. 7 for different radii compared to the $2 \mathrm{D}$ model results at $x=0.5 \mathrm{~mm}$.

one using bonded magnets. Even though it is not easy yet to obtain Nd-Fe-B bonded magnets with a magnetization higher than $0.9 \mathrm{~T}$, the possibility to realize almost any shape allows ingenious magnetic structures to be made in order to compensate. In particular, the ellipsoidal structure shown in this paper permits to create an intense magnetic field concentrated on the voice-coil trajectory, which is the aim of a leakage free loudspeaker motor. Furthermore, one significant advantage of bonded magnets is that the making of such structures is facilitated, since neither assembling nor fabrication are needed. As a result, in case of a mass production, it is much cheaper to produce.

\section{REFERENCFS}

[1] M. Gander, "Moving-coil loudspeaker topology as an indicator of linear excursion capability," J. Audio Eng. Soc., vol. 29, pp. 10-26, Jan 1981.

[2] J. Vanderkooy, "A model of loudspeaker driver impedance incorporating Eddy currents in the pole structure," J. Audio Eng. Soc, vol. 37, pp. 119128, March 1989.

[3] C. Koh, "Magnetic pole shape optimization of permanent magnet motor for reduction of cogging torque," IEEE Trans. Magn., vol. 33, pp. 1822 1827, Feb 1997.

[4] K. Atallah and D. Howe, "The application of halbach cylinders to brushless ac servo motors," IEEE Transactions on Magnetics, vol. 34, pp. 2060-2062, april 1998.

[5] M. Berkouk, V. Lemarquand, and G. Lemarquand, "Analytical calculation of ironless loudspeaker motors," IEEE Trans. Magn., vol. 37. pp. 1011-1014, March 2001.

[6] G. Lemarquand, "Ironless loudspeakers," IEEE Transactions on Magnetics, vol. 43, pp. 3371-3374, August 2007.

[7] W. House, "Transducer motor assembly," US Patent 5,142,260, 1992.

[8] Ohashi, "Magnetic circuit and speaker," Patent EP 1553802 A2, 2005.

[9] Z. Jibin, Z. Jiming, and H. Jianhui, "Design and pressure control of highpressure differential magnetic fluid seals," IEEE Trans. Magn., vol. 39. pp. 2651 - 2653, Sept 2003.

[10] J. P. Yonnet, Rare-earth Iron Permanent Magnets, ch. Magnetomechanical devices. Oxford science publications, 1996.

[11] F. Bancel and G. Lemarquand, "Three-dimensional analytical optimization of permanent magnets alternated structure," IEEE Trans. Magn., vol. 34, pp. 242-247, January 1998.

[12] H. L. Rakotoarison, J. P. Yonnet, and B. Delinchant, "Using coulombian approach for modelling scalar potential and magnetic field of a permanent magnet with radial polarization," IEEE Trans. Magn., vol. 43. pp. 1261-1264, April 2007.

[13] R. Ravaud, G. Lemarquand, V. Lemarquand, and C. Depollier, "Analytical calculation of magnetic field created by permanent magnet rings," IEEE Trans. Magn., vol. 37, June 2008 